\title{
Türkiyenin doğusunda II. basamak bir devlet hastanesinin perkütan endoskopik gastrostomi deneyimi
}

Percutaneous endoscopic gastrostomy: Experience in a secondary-level hospital in the eastern part of Turkey

(D) Rifat PEKSÖZ ${ }^{1}$, (D) Serkan BORAZAN ${ }^{2}$

Muș Devlet Hastanesi, ${ }^{1}$ Genel Cerrahi Bölümü, ${ }^{2}$ Gastroenteroloji Bölümü, Mus

Giriş ve Amaç: Uzun süre beslenecek hastalarda enteral yol parenteral yola göre daha avantajlıdır. Perkütan endoskopik gastrostomi diğer gastrostomi yöntemlerine göre daha avantajlı bir enteral beslenme çeşididir. Bu çalışmada Türkiye'nin doğu kesiminde II. basamak bir devlet hastanesinde perkütan endoskopik gastrostomi takılan hastaları literatür verileri eşliğinde tartışmayı amaçladik. Gereç ve Yöntem: Muş Devlet Hastanesi endoskopi ünitesinde Ocak 2017-Aralık 2019 tarihleri arasında perkütan endoskopik gastrostomi tüpü takılmış 30 hastaya ait veriler retrospektif olarak incelendi. Bulgular: Çalışmaya yaşları 18 ile 95 arasında olan 30 hasta alındı ve hastaların yaş ortalaması 68 yıl idi. Hastalar azalan sırasıyla anestezi yoğun bakım, nöroloj servisi, palyatif bakım birimi, genel yoğun bakım, dahiliye servisi, göğüs hastalıkları biriminden perkütan endoskopik gastrostomi işlemi için konsülte edildi. Perkütan endoskopik gastrostomi takılan hastaların endikasyonlar azalan sirasıyla; serebrovasküler olay, hipoksik iskemik ensefalopati, Alzheimer, Parkinson, demans, amiyotrofik lateral skleroz, özofagus kanseri, subakut sklerozan panensefalit, aspirasyon pnömonisi, miyokard enfarktüsü, beyin cerrahi ameliyatı sonrası, elektrik çarpması sonucu oral alamayan (quadriplejik) hastalar idi. Hastalarımızda işlem sonrası majör komplikasyon gözlenmedi. Minör komplikasyon oranı 7/30 (\%23) idi. Sonuç: Perkütan endoskopik gastrostomi uzun dönem beslenme gereksinimi olan hastalar için enteral beslenmenin en güvenilir yoludur. Perkütan endoskopik gastrostomi işlemi II. basamak hastanelerde de kolaylıkla ve güvenle yapılabilir.

Anahtar kelimeler: Enteral beslenme, perkütan endoskopik gastrostomi, endikasyon, komplikasyon

\section{GİRISS}

Gastrointestinal sistem fonksiyonları normal olmasına rağmen oral yoldan beslenemeyen hastalarda; gastrointestinal mukozanın bütünlüğunün korunması, intestinal immün yanıt ve normal flora yapı devamlılığının sağlanması, mukozal bariyer fonksiyonunun korunması için, hastaların enteral yol ile beslenmesi daha iyidir (1). Enteral beslenme için; perkütan endoskopik gastrostomi (PEG), nazogastrik veya nazojejunal tüp, cerrahi gastrostomi, cerrahi jejunostomi, radyolojik gastrostomi gibi çeşitli yöntemler kullanılabilir (2). PEG işlemi, oral yolla beslenemeyen ve gastrointestinal sistem fonksiyonları normal olan hastalardın uzun süreli enteral beslenmesi için tercih edilen bir yöntemdir. Gauderer ve Ponsky ilk olarak 1980 yılında çocuklarda uygulamıştır (3). Genel anestezi gerektirmeden yapılabilmesi, cerrahiye göre daha az invaziv
Background and Aims: In patients who cannot ingest sufficient nutrients orally and who are required to be fed for a long time, enteral nutrition (tube feeding) is considered to be a more advantageous option than parenteral nutrition. Percutaneous endoscopic gastrostomy is the preferred method for delivering enteral nutrition compared to other gastrostomy methods. In this study, we aimed to discuss literature reports concerned with patients who underwent percutaneous endoscopic gastrostomy in a secondary-level state hospital in the east of Turkey. Materials and Methods: We performed a retrospective analysis of 30 patients receiving enteral nutrition after undergoing a percutaneous endoscopic gastrostomy between January 2017 and December 2019 at the Muss State Hospital Endoscopy Unit. Results: Thirty patients were included in this study. The mean age of patients was 68 (18-95) years. Patients were consulted according to the following order: the anesthesia intensive care unit, neurology service, palliative care unit, general intensive care unit, internal medicine service, and chest diseases department. The patients had cerebrovascular diseases, hypoxic ischemic encephalopathy, Alzheimer's, Parkinson's disease, dementia, amyotrophic lateral sclerosis, esophageal cancer, subacute sclerosing panencephalitis, aspiration pneumonia, and myocardial infarction, after brain surgery, as a result of electric shock (quadriplegic). After undergoing percutaneous endoscopic gastrostomy, the indications of the patients decreased. Major complications were not observed in our patients. The minor complications rate was 7/30 (23\%). Conclusion: Percutaneous endoscopic gastrostomy is the most reliable way to deliver enteral nutrition to patients with long-term nutritional needs. Percutaneous endoscopic gastrostomy procedure can be easily and safely performed in secondary-level hospitals.

Keywords: Enteral nutrition, percutaneous endoscopic gastrostomy, indication, complication

bir işlem olması, işlem süresinin kısa olması, maliyetinin düşük olması ve hastaya sağlanan nütrisyonel desteğin etkili bir şekilde sağlanması uygulama sıklı̆̆ını arttırmıştır.

Bu çalışmada Türkiye'nin doğu kesiminde II. basamak bir devlet hastanesinde PEG takılan hastaların demografik özelliklerini, PEG takılma endikasyonlarını, işlem sonrası gelişen komplikasyonlarını, hastaların takipleri ile ilgili verileri literatür eşliğinde tartışmayı amaçladık.

\section{GEREC ve YÖNTEM}

Hastanemiz Endoskopi ünitesinde Ocak 2017-Aralık 2019 tarihleri arasında PEG işlemi yapılan 30 hasta retrospektif olarak incelendi. Hastaların cinsiyeti, yaşı, primer hastalığı (PEG 
takılma endikasyonu), işleme bağlı komplikasyonlar, ek hastalıkları, takip süreleri gibi bilgiler değerlendirildi. Işlem öncesi hasta ve yakınlarına işlem ile ilgili bilgi verildikten sonra hasta rıza onam formu imzalatıldı. Isslem öncesi hastaların en az 8 saat enteral beslenmesi kesildi. Özofagogastroduodenoskopi cihazı ile gastroenteroloji uzmanı tarafindan duodenum üçüncü kıtaya kadar ilerlendi. Patoloji saptanmayan hastalarda PEG işlemi genel cerrahi uzmanı tarafından uygulandı. İslemler anestezi uzmanı kontrolünde yapıldı. Tüm hastalar monitörize edildi ve oksijen desteği altında işlem yapıldı. İslem öncesi hastalara oral lokal anestezi (\%10 lidokain sprey) ile birlikte sedasyon (midazolam $0.05 \mathrm{mg} / \mathrm{kg}$ ) uyguland. Gastroskopla işık reflesi ve parmak fluktuasyonuyla ponksiyon yapılacak yer belirlendi. Sterilazyon şartları sağlandıktan sonra direkt görüş altında iğneli guide ile mideye girildi. Endoskopik punchla PEG ipi tutularak skop yardımıyla ağıdan çıkarıldı. Standart 16-20 f silikon PEG kiti kullanıldı. Mideye PEG tüpü yerleştirilirken gastroskopla mide tekrar eksplore edildi. Mide içinde kanama kontrolü yapıldıktan sonra kateterden sıvı verilerek mideye sorunsuz geçtiği gözlendi. İşlem sonrası tüp serbest drenaja alındı. 24 saat sonrası önce su verilerek mide rezidü durumuna göre kademeli olarak hastalar beslenmeye başlandi.

Bu çalışma için Erzurum Bölge Eğitim ve Araştırma hastanesi Klinik Araştırmalar Etik Kurulundan onay alınmıştır (17.03.2020 tarih ve 37732058-514.10 sayı ile).

\section{BULGULAR}

Çalışmaya 19 erkek (\%59) ve 13 kadın (\%41) olmak üzere toplam 32 hasta dahil edildi. Yaşları 18 ile 95 arasında değişen hastaların yaş ortalaması 68'dir. Bir hastada geçirdiği batın operasyonları nedeniyle transluminasyon sağlanamadığından ve bir hastada da diyafragmadan kolon herniasyonu saptandığından işlem yapılamadı. Toplam 30 hastanın verileri literatür eşliğinde incelendi.

Hastalar anestezi yoğun bakım, nöroloji servisi, palyatif hasta bakım birimi, genel yoğun bakım, dahiliye servisi, göğüs hastalıkları biriminden PEG işlemi için konsülte edildi (Tablo 1). PEG takılan hastaların endikasyonları, serebrovasküler olay, hipoksik iskemik ensefalopati, Alzheimer, Parkinson, demans,

\section{Tablo 1. Hastaların kliniklere göre dağılımı}

\begin{tabular}{|lcc} 
& n & \% \\
\hline Anestezi-yoğun bakım & 13 & 43.3 \\
Nöroloji & 8 & 26.6 \\
\hline Palyatif birimi & 5 & 16.6 \\
Genel yoğun bakım & 2 & 6.6 \\
Dahiliye servisi & 1 & 3.3 \\
Göğüs hastalıkları & 1 & 3.3 \\
Toplam & 30 & 100
\end{tabular}

amyotrofik lateral skleroz, opere özofagus kanseri, subakut sklerozan panensefalit, aspirasyon pnömonisi, miyokard enfarktüsü, beyin cerrahi ameliyatı sonrası, elektrik çarpması sonucu (quadriplejik) enteral beslenemeyen hastalar idi (Tablo 2). Ilave hastalıkları incelendiğinde, 10 hastada (\%33.3) hipertansiyon, 7 hastada (\%23.3) koroner arter hastalığı, 4 hastada (\%13.3) diabetes mellitus, 3 hastada (\%10) KOAH, 3 hastada (\%10) kalp yetmezliği, 2 hastada (\%6.6) böbrek yetmezliği mevcuttu ve 11 (\%36.6) hastada ek hastalık saptanmadı (Tablo 3).

Hastalarımızda majör komplikasyon gelişmedi. Minör komplikasyon olarak 4 hastada (\%13) peristomal sızıntı, 3 hastada (\%10) periostamal enfeksiyon, 2 hastada (\%6) tüp tıkanıklığ ve 1 hastada tüpte sızıntı yaşandı. Tüpteki sızıntı fazla olan hastada tüpü çıkarmak zorunda kalındı, diğer hastalar yara bakımı tedavisiyle iyileşti (Tablo 4). Hastaların ortalama yaş ve takip edildiği süreler ve mortalite takipleri kaydedildi (Tablo 5).

\begin{tabular}{lcc|}
\hline Tablo 2. PEG takılma endikasyonları & & \\
\hline Serebrovasküler olay & n & $\%$ \\
\hline Hipoksik iskemik ensefalopati (Post. CPR) & 13 & 43.3 \\
\hline Alzheimer, Parkinson, demans & 5 & 16.6 \\
\hline Amiyotrofik lateral skleroz & 3 & 10 \\
\hline Ozefagus kanseri & 1 & 10 \\
\hline Subakut sklerozan panensefalit & 1 & 3.3 \\
\hline Aspirasyon pnömonisi & 1 & 3.3 \\
\hline Miyokard enfarktüsü & 1 & 3.3 \\
\hline Beyin cerrahi ameliyatı sonrası & 1 & 3.3 \\
\hline Elektrik çarpması sonucu (quadriplejik) & 1 & 3.3 \\
\hline Toplam & 30 & 100
\end{tabular}

Tablo 3. Hastaların yandaş hastalıkları

\begin{tabular}{lcc} 
& n & \% \\
\hline Hipertansiyon & 10 & 33.3 \\
\hline Koroner arter hastalı̆̆ı & 7 & 23.3 \\
\hline Diyabetes mellitus & 4 & 13.3 \\
\hline KOAH & 3 & 10 \\
Kap yetmezliği & 3 & 10 \\
Böbrek yetmezliği & 2 & 6.6 \\
Yandaş hastalık yok & 11 & 36.6 \\
Toplam & 30 & 100
\end{tabular}

KOAH: Kronik obstrüktif akciğer hastalığı.

Tablo 4. Katetere bağlı komplikasyonlar

\begin{tabular}{lcc} 
& n & \% \\
\hline Periostomal sızıntı & 4 & 13.3 \\
\hline Periostomal enfeksiyon & 3 & 10 \\
Tüp tıkanıklığı & 2 & 6.6 \\
Tüpün çıkması & 1 & 3.3
\end{tabular}


Tablo 5. Hastaların ortalama yaş ve takip süreleri

Exitus Olan Hastalar $(\mathbf{n}=17)$

\author{
Ortalama yaş \\ Ortalama takip süresi (gün)
}

\section{7}

51
Halen Yaşayan Hastalar $(n=13)$ 54

331
Tüm Hastalar $(\mathbf{n}=30)$

68

172

\section{TARTISSMA}

Uzun süre beslenecek hastalarda, enteral yolun parenteral yola göre; daha rahat ve kolay uygulanabilir olması, daha ekonomik olması, mukozal atrofiyi önlemesi, bağırsak florasinı koruması, bakteriyal translokasyonu azaltması gibi avantajları vardır. Uzun süreli beslenme planlanan hastalarda; nazoenteral yöntemlerin nazofarengeal erozyonlar, sinüzit, akut otitis media, özofajitis, özofagus varis yırtılması ve özofagus ülserasyonu gibi dezavantajları vardır $(1,4)$. Bu yöntemlerin uygulama güçlükleri ve komplikasyonları nedeniyle gastrostomi yöntemleri kullanılmaya başlanmıştır. Günümüzde PEG geleneksel gastrostominin yerini almıştır (5).

Kinik pratikte uzun dönem beslenmeler için PEG tavsiye edilen bir yöntemdir. PEG, ağızdan beslenemeyen enteral beslenmenin 2-3 haftadan uzun süreceği düşünülen hastalarda ESPEN (The European Society for Clinical Nutrition and Metabolism) tarafından önerilmektedir (6). Bazı çalışmalarda ise bu süre enteral beslenme ihtiyacı 4 haftadan daha uzun sürecek hastalar için önerilmektedir (7).

PEG kateteri takmak için başlıca üç teknik kullanılmaktadır. Bunlar pull (Ponsky-Gauderer pull teknik), push (Sacks-Vine push teknik) ve introducer'dir (10). Biz de hastalarımızda en sık kullanılan pull (çekme) tekniğini kullandık. Birçok farklı merkezli çalışmada PEG yerleştirme başarı oranının \%94-99 olduğu görülmüştür (9). Bizim yaptığımız çalışmada başarı oranımız \%93 (30/32) idi. 2 hastaya PEG takılamadı. Bir hastada translüminasyon sağlanmadı. Bir hastada da birkaç kez batın cerrahisi geçirmesi nedeniyle işlem başarılı olmadı. PEG işlemi sonrası beslenme zamanı ve şekli için literatürde görüş birliği sağlanamamıştır. Yapılan çalışmalarda 12-24 saat içerisinde tüpten beslemeye başlanılması önerilmektedir (11). Bizim pratiğimizde işlemden 24 saat sonra tüpten $20 \mathrm{cc}$ su verildikten sonra 12 saat içerisinde tüpün etrafinda sızdırma olmadığı görüldükten sonra enteral beslenmeye başlandı.

PEG takılma endikasyonları; serebrovasküler olaylar, beyin travması, baş-boyun ve özofagus tümörleri, bulber parezi, Parkinson hastalığı, amiyotrofik lateral sklerozis, nöromüsküler hastalıklar, serebral palsi, politravma ve uzun süreli koma hali gibi durumlar en sık endikasyonlardır (8). Temiz ve arkadaşlarının yaptığı 64 hastalık bir seride hastaların \%48'i anestezi ve reanimasyon, \%32.8'i nöroloji kliniklerinden konsülte edilen hastalardı. Endikasyon olarak \%51.5 ile serebrovasküler hastalıklar birinci sırada gelmektedir (9). Bizim çalışmamızdaki literatüre benzer şekilde hastaların \%43.3'ü anestezi ve reanimasyon, \%26.6'sı nöroloji klinikle- rinden konsülte edilmişti. Endikasyon olarak serebrovasküler hastalıklar \%53.3 ile birinci sirada gelmektedir.

PEG işlemi için profilaktik antibiyotik kullanımı tartışmalı bir konudur. Birçok çalışmada periostomal enfeksiyonu azalttığ düşünülse de, diğer çalışmalarda bakteriyel rezistans nedeniyle karşıt görüş bildirmişlerdir (12). Bizim çalışmamızda hastalar takip edilen kliniklerce primer hastalığından dolayı antibiyotik tedavisi aldığı için rutinde proflaktik antibiyotik kullanımı yapılmadı. Çalışmalarda periostomal enfeksiyon oranı \%5-36 arasında değişmektedir $(13,14)$. Bizim hastalarımızda enfeksiyon oranı yüzde 10 olup literatürle paralellik göstermektedir.

PEG; minimal invaziv bir işlem olmasına rağmen istenmeyen majör ve minör komplikasyonları vardır. En önemli majör komplikasyonlar; gastrik perforasyon, gastrokolik fistül ve peritonittir. En önemli minör komplikasyonlarsa; tüpün çıkması, kırılması, tıkanması, periostomal deri enfeksiyonu, periostomal sızıntı ve kanamadır (15). PEG işlemine bağlı olarak \%4-13.6 oranında komplikasyon görülebilmektedir (16). PEG ile ilgili mortalite oranı \%l'in altında bildirilmiştir (1). Bizim çalışmamızda işleme bağlı mortalite görülmedi. Hastaların \%36'sı (11 hasta) ilk 1 ay içerisinde primer hastalığa sekonder kaybedildi. PEG işlemine bağlı majör komplikasyon görülmedi. Minör komplikasyolar; üç hastada (\%10) periostamal enfeksiyon, dört hastada (\%13 ) periostamal sızıntı gelişti ve hastalar yara yeri bakımı tedavisiyle iyileşti. İki hastada (\%6) tüp tıkanıklığı gelişti. Bu iki hastanın gastrostomi tüpü tıkanıkları, tüp içerisinden endoskopik forseps gönderilerek açıldı. Bir hastada (\%3) tüp çıktı, çıkan tüp yerine 18 numara foley sonda yerleştirildi ve bir hastada (\%3) sızıntı fazla olduğu için takılan gastrostomi tüpü çıkarıldı. Hastalarımızda toplam komplikasyon oranı 7/30 (\%23) literatüre göre yüksekti ancak komplikasyonlar minör komplikasyonlar olmakla birlikte yüksek olmasının nedeninin hastaların PEG takip kayıtlarının iyi tutulmasından kaynaklandığını düşünmekteyiz.

Sonuç olarak; uzun süre beslenme ihtiyacı olan hastalarda parenteral yoldan beslenmenin komplikasyonlarından kaçınmak için PEG enteral beslenmenin en güvenilir yoludur. Türkiye'nin kirsal kesiminde bir devlet hastanesinde elde edilen sonuçlar incelediğinde literatürle benzer sonuçlar elde edilmiştir. Hastaların PEG işlemi için ileri merkeze sevkedilmesinin hastalara ve sağlığa getirdiği maliyet yükü de göz önünde bulundurulduğunda PEG işlemi II. basamak hastanelerde de kolaylıkla ve güvenle yapılabilir.

\footnotetext{
"Tüm yazarlar herhangi bir çıkar çatışması olmadığını kabul ederler."
} 


\section{KAYNAKLAR}

1. Marik PE, Zaloga GP. Early enteral nutrition in acutely ill patients: a systematic review. Crit Care Med 2001;29:2264-70.

2. Strijbos D, Keszthelyi D, Bogie RMM, et al. A systematic review and meta-analysis on outcomes and complications of percutaneous endoscopic versus radiologic gastrostomy for enteral feeding. J Clin Gastroentero 2018;52:753-64

3. Gauderer MW, Ponsky JL, Izant RJ. Gastrostomy without laparotomy: a percutaneous endoscopic technique. J Pediatr Surg 1980;15:872-5.

4. Bassem YS, Jeffrey MM, Jeffrey LP. Percutaneous endoscopic gastrostomy. Lightdale CJ, (eds). Gastrointestinal Endoscopy, Philadelphia: WB Saunders Company, 1998; 551-63.

5. Fortunato JE, Cuffari C. Outcomes of percutaneous endoscopic gastrostomy in children. Curr Gastroenterol Rep 2011;13:293-9.

6. Löser C, Aschl G, Hébuterne X, et al. ESPEN guidelines on artificial enteral nutrition-percutaneous endoscopic gastrostomy (PEG). Clin Nutr $2005 ; 24: 848-61$

7. Bankhead R, Boullata J, Brantley S, et al. Enteral nutrition practice recommendations. JPEN J Parenter Enteral Nutr 2009;33:122-67.

8. Şenlikçi A, Kuzu UB, Dede F, Fidan K. Percutaneous endoscopic gastrostomy: Experience in a secondary level hospital. Endoscopy Gastrointestinal 2018;26:95-8.
9. Temiz A, Aslan OB, Albayrak Y, et al. Percutaneous endoscopic gastrostomy: indications and complications. Akademik Gastroenteroloji Dergisi 2015; 14:113-6

10. Hucl T, Spicak J. Complications of percutaneous endoscopic gastrostomy. Best Pract Res Clin Gastroenterol 2016;30:769-81.

11. Ali T, Le V, Sharma T, et al. Post-PEG feeding time: a web based national survey amongst gastroenterologists. Dig Liver Dis 2011;43:768-71.

12. Yuruker S, Koca B, Karabicak I, Kuru B, Ozen N. Percutaneous endoscopic gastrostomy: Technical problems, complications, and management. Indian J Surg 2015;77(Suppl 3):1159-64.

13. Faias S, Cravoi M, Claro I, LaGE P, Nobre-Leitao C. High rate of percutaneous endoscopic gastrostomy site infections due to oropharyngeal colonization. Dig Dis Sci 2006;51:2384-8.

14. McClave SA, Chang WK .Complications of enteral access. Gastrointest Endosc 2003;58:739-51.

15. Foutch PG. Complications of percutaneous gastrostomy and jejunostomy. Recognition, prevention and treatment. Gastrointest Endosc Clin N Am 1992;2:231-48.

16. Akay MA, Yayla D, Elemen L, et al. Percutaneous Endoscopic Gastrostomy; Experience of two clinics. Sakaryamj 2014;4:70-3. 